\title{
Eocene round herring from Monte Bolca, Italy
}

Giuseppe Marramà and Giorgio Carnevale

Acta Palaeontologica Polonica 60 (3), 2015: 701-710 doi:http://dx.doi.org/10.4202/app.00057.2014

Fishes of the subfamily Dussumieriinae, also known as round herrings, are a small subgroup of the family Clupeidae inhabiting tropical and subtropical marine coastal waters. A new genus and species of round herring, Trollichthys bolcensis gen. et sp. nov., is described from the lower Eocene micritic limestone of Monte Bolca, northern Italy. This new clupeid taxon is based on seven partially complete articulated skeletons that exhibit a unique combination of features, including: two supramaxillae, edentulous jaw and palate bones, 41-42 preural vertebrae and 22-24 pleural ribs, pleural ribs-preural vertebrae ratio ranging $0.52-0.57$, five or six supraneural bones, dorsal-fin origin located at about mid-length of the body, dorsal fin with about 16 rays, two postcleithra, pelvic-fin insertion slightly behind the dorsal-fin origin, and pelvic fin with eight rays. Trollichthys bolcensis shares several features with the extant round herring genus Spratelloides. However, because of its unique combination of features, Trollichthys bolcensis cannot be confidently assigned to any of the extant dussumieriine lineages and present evidence does not favour any particular sister-group relationship.

Key words: Teleostei, Clupeidae, Trollichthys bolcensis, Eocene, Ypresian, Italy, Pesciara quarry.

Giuseppe Marramà [giuseppe.marrama@unito.it], Dipartimento di Scienze della Terra, Università degli Studi di Torino, via Valperga Caluso, 35, 10125 Torino, Italy; Giorgio Carnevale [giorgio.carnevale@unito.it] (corresponding author), Dipartimento di Scienze della Terra, Università degli Studi di Torino, via Valperga Caluso, 35, 10125 Torino, Italy.

This is an open-access article distributed under the terms of the Creative Commons Attribution License (for details please see creativecommons.org), which permits unrestricted use, distribution, and reproduction in any medium, provided the original author and source are credited. 
FoF Full text $(819.1 \mathrm{kB})$ 